\title{
Electron Microprobe Quantitative Mapping vs. Defocused Beam Analysis
}

\author{
$\underline{\text { Julie E. Barkman }}^{1}$, Paul Carpenter ${ }^{2}$, Ji-Cheng Zhao ${ }^{3}$, and John J. Donovan ${ }^{1}$ \\ 1. University of Oregon, CAMCOR, Eugene, OR, USA \\ 2. Washington University, Department of Earth and Planetary Sciences, St. Louis, MO, USA \\ 3. The Ohio State University, Department of Materials Science and Engineering, Columbus, OH, USA
}

Despite consensus within the electron microprobe community that broad or defocused beam analyses (DBA) provide erroneous results [1-4], the technique still remains in use [5-7]. Analytical errors associated with this practice are usually attributable to heterogeneous interaction volumes, caused by the presence of multiple phases. Traditional matrix corrections used in EPMA assume that the interaction volume is homogeneous; therefore, when phase boundaries are encountered, elemental concentrations are often inappropriately corrected. Because x-ray absorption dominates the matrix correction, average compositions are typically overcorrected for the emission lines of interest, thus resulting in high totals. Attempts have been made to improve the accuracy of these analyses by weighting the abundances of each element and phase present [1,8], as well as the density of each component [2,9]. While such corrections appear to yield more accurate results, they require additional knowledge of the sample (modal abundances and phase compositions) and do not seem to be as rigorous as other methods of determining bulk compositions $[3,4]$.

In this study quantitative $\mathrm{x}$-ray maps were used to show the magnitude of error that can be associated with DBA and to highlight analytical methods that can be used to avoid the use of complicated correction factors. Two maps along the diffusion zone of an $\mathrm{Al}-\mathrm{Mg}_{95} \mathrm{Gd}_{5}$ diffusion couple were acquired using Probe Image with a focused beam, one larger area (Area A, Fig. 1A) and one smaller area within the most heterogeneous portion of the diffusion boundary (Area B, Fig. 1B). Both maps were acquired at $15 \mathrm{keV}$ and $30 \mathrm{nA}$. On- and off-peak maps of $\mathrm{Mg}, \mathrm{Sn}, \mathrm{Gd}, \mathrm{Sn}, \mathrm{Al}$, and $\mathrm{O}$ were collected for both areas; both high and low off-peak maps were acquired for Area A, while only high off-peak maps was acquired for Area B. The on- and off-peak maps were then utilized to create quantitative element maps using CalcImage. Using Golden Software's Surfer ${ }^{\circledR}$ program, each elemental map was then averaged in horizontal strips two different ways to show the effects of performing DBA: one with the weight percent for each individual point in the strip averaged, weight percent determined from the intensity measured for that point; one with the intensities for all points in a strip averaged, with that average then converted into a weight percent (simulating DBA). $1 \mu \mathrm{m}$ and $8 \mu \mathrm{m}$ wide strips were averaged across $64 \mu \mathrm{m}$ Area A and $256 \mu \mathrm{m}$ in Area B.

As shown in Fig. 1C and 1D, the simulated DBA data often deviates from the averaged weight percent data for the same strip. Mg showed large variations in weight percent between the two methods, however, not every element analyzed exhibited these incongruities; the nature and concentration of each element is likely responsible for some of this effect. Differences of up to $\sim 4 \mathrm{wt} . \%$ absolute can be seen between the defocused beam and average weight percent for $\mathrm{Mg}$ (Fig. 1C and1D). The non-uniformity of the disparities, over and under correcting by varying amounts, underscores the importance of using a more reliable method for determining the bulk composition of a heterogeneous material. Since the composition for each pixel can be determined and then averaged across any size area desired, utilizing these quantitative $\mathrm{x}$-ray maps appears to be a more accurate method to determine average areal compositions. While there is some decrease in precision due to shorter counting times per point, for 
major elements this seems to be an advantageous tradeoff for the increased accuracy obtained. Subsequently, these quantitative concentration maps can also be clustered statistically to determine the phases present and, with user-specified densities, the modal mass abundance of each phase.

\section{References:}

[1] A Albee et al, $8^{\text {th }}$ Lunar and Planetary Science Conference (1977), p. 7.

[2] P Warren, $28^{\text {th }}$ Lunar and Planetary Science Conference (1997), p. 1406.

[3] J Berlin et al, $37^{\text {th }}$ Lunar and Planetary Science Conference (2006), p. 2370.

[4] J Berlin et al, Microscopy and Microanalysis 14 (2008), p.110.

[5] S Noguchi et al, Journal of Volcanology and Geothermal Research 175 (2008), p. 71.

[6] H McSween, Geochimica et Cosmochimica Acta 43 (1979), p. 1761.

[7] M Kimura et al, Meteoritics and Planetary Science 40 (2005), p.855.

[8] J Bower et al, $8^{\text {th }}$ International Congress on X-ray Optics and Microanalysis (1977), p. 182.

[9] P Carpenter et al, 40 ${ }^{\text {th }}$ Lunar and Planetary Science Conference (2009), p. 2531.
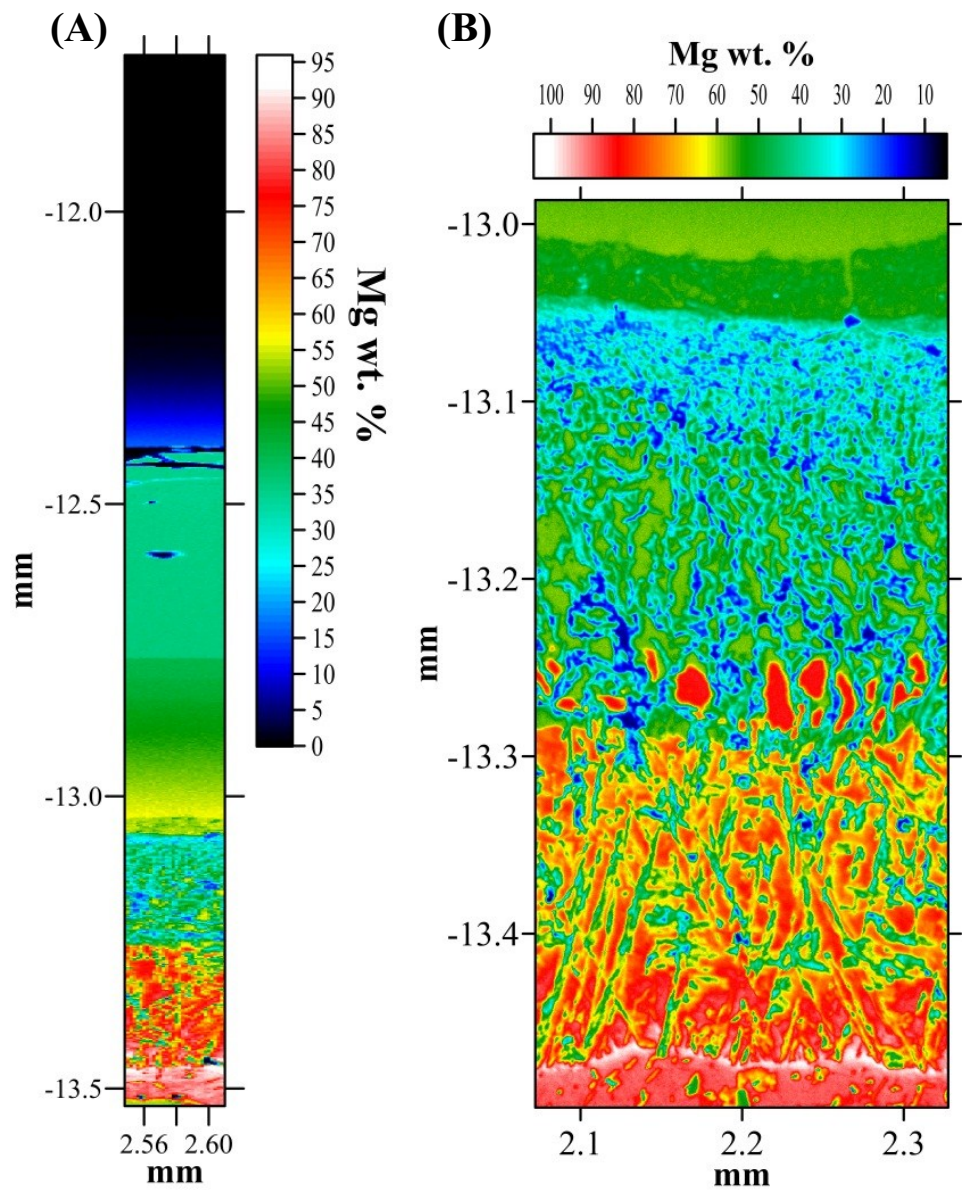

(C)

(D)

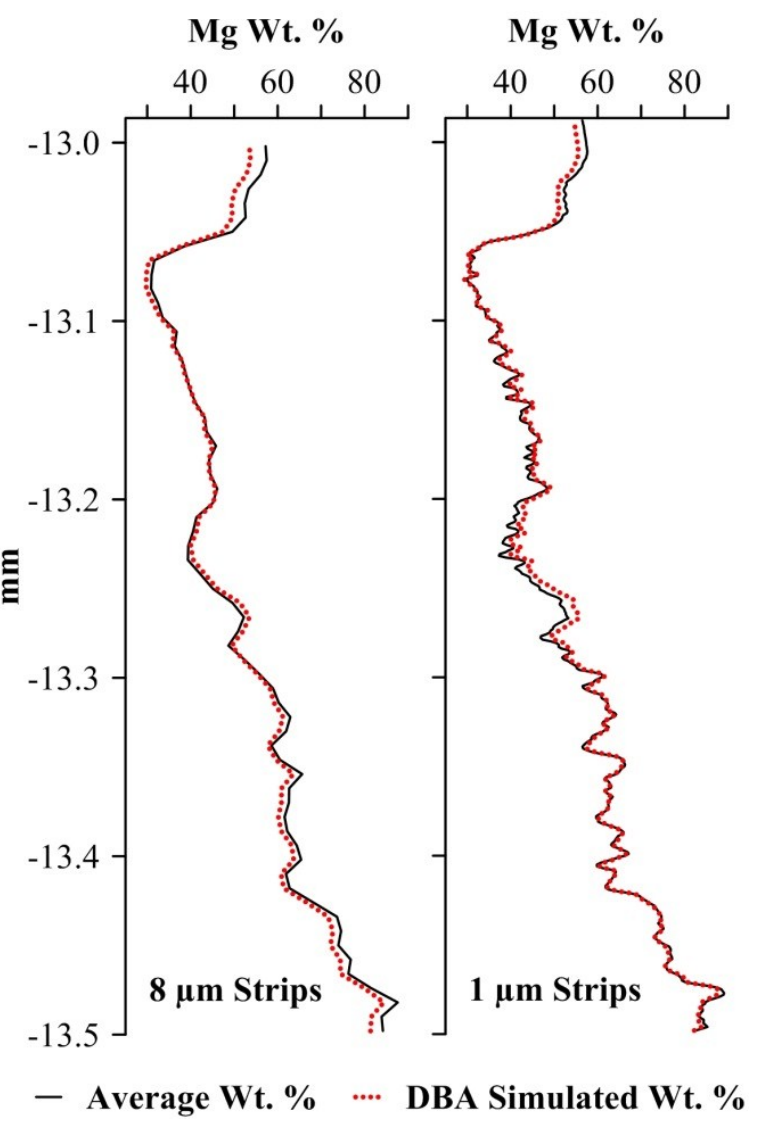

Figure 1. (A) Area A, Mg quantitative map: $64 \mu \mathrm{m}$ by $1800 \mu \mathrm{m}, 32$ pixels by 900 pixels, $2 \mu \mathrm{m}$ by $2 \mu \mathrm{m}$ pixels, $600 \mathrm{~ms} /$ pixel on-peak, and $100 \mathrm{~ms} /$ pixel off-peak; (B) Area B, Mg quantitative map: $256 \mu \mathrm{m}$ by $512 \mu \mathrm{m}, 512$ pixels by 1024 pixels, $0.5 \mu \mathrm{m}$ by $0.5 \mu \mathrm{m}$ pixels, $500 \mathrm{~ms} /$ pixel on-peak, and $50 \mathrm{~ms} /$ pixel off-peak; (C) Average wt. \% of Mg in $8 \mu \mathrm{m}$ strips, Area B; (D) Average wt. \% of Mg in $1 \mu \mathrm{m}$ strips, Area B. 